\title{
Does the Concept of Loss Orient Risk Prevention Policy?
}

\author{
Dominique Pecaud
}

\begin{abstract}
This chapter examines the concept of loss and damage and how they are used in a political and moral context. It takes as a starting point the nuclear accident of Fukushima Daiichi and the short, medium and long-term consequences for the human and non-human environment. It also identifies some potential elements for the transformation of the disaster into a catastrophe, and how we can develop different forms and scales of resilience.
\end{abstract}

Keywords Loss - Damage - Market - Gift - Catastrophe $\cdot$ Resilience

\section{Introduction}

The French word dommage (damage) has several translations into English. Two are of particular interest: first, it is the partial or total physical destruction of a living being (ranging from physical injury to death) or an object, due to an accident; second, it represents loss, as in the expression "it's a pity" or "what a pity".

This polysemy makes it difficult to create an empirical concept in the sense of a class of objects that can be characterized by the elements that compose it. But why even try? Because a deeper understanding of the anthropological meaning of damage can help to identify social dynamics that receive little attention in classical risk prevention studies [1]. In practice, the word appears to designate both the consequences of a disaster, and the losses suffered by humans and non-humans which are serious enough for it to be asserted that the disaster must not happen again. In this case, taking damage and its dynamics into account can help to go beyond the simple issue of loss.

\section{Pecaud}

Université de Nantes, Nantes, France

D. Pecaud ( $\square)$

Centre for Research on Risks and Crises (CRC), MINES ParisTech/PSL Research University,

Paris, France

e-mail: dominique.pecaud@univ-nantes.fr 
The problem is this: the definition of disasters and resilience to their effects cannot be addressed if the issue remains limited to the usual collective representations and ways of thinking about risk prevention that - as disasters demonstratefail. A change is in order. This study advances a concept of damage and its technical, economic, political and moral usage. It addresses the Fukushima Daiichi nuclear accident and its consequences in the short, medium and long term; not just as a simple accident, but as a way of life that is both individual and universal, for a human and non-human environment that has passed into history.

Human and non-human: the expression comes from the sociology of objects, which [2] remind us is an extension of the sociology of innovation and the pragmatic sociology of action. This sociology seeks to overcome epistemological divisions such as those between the individual and the collective, or methodological individualism and determinism. To this we can add the accident and the essence. It aims to repopulate the sociological universe with the set of objects that, according to [3] participate in the construction of society, unlike the roles found in classical sociological theory: faithful tools, critical infrastructure or, finally, projection screen.

Loss can be defined as a system of representations and actions following an event. It is contemporary with the construction and designation of victims. This conceptual definition is part of a political philosophy. It is based on the role of organizations and various forms of authority in shaping collective action and therefore, the creation of the common good.

Rather than take a traditional approach, this chapter presents a series of viewpoints that address both theoretical and practical aspects of the concept of loss. It is argued that loss should be understood both as a moral or legal heuristic ${ }^{1}$ and as an actant [5] that is able to change form depending on the circumstances in which it is used.

\section{Industrial Degradation, Causal Links and Preventive Maintenance}

The degradation of an environment can be seen from outside the subject, i.e. as an object. In this case, the issue of loss has no emotional connotations for the person who observes it. If we consider the consequences of the nuclear accident at Fukushima Daiichi, there are many reasons for this indifference: lack of information, mistrust regarding its content or source, geographical remoteness, few signs of

\footnotetext{
${ }^{1}$ In law, two elements define the concept of loss: (a) although there may be no damage as such, there is a causal relationship - it can be connected to something. "Loss is simply any harm caused by something. It is this cause that does harm and that gives rise to the legal concept of loss; in other words, loss does not exist naturally" [4]; (b) When the cause is natural, the law will only consider common-sense explanations that throw light on the causal link. Loss differs from harm, harm being defined as the result of loss.
} 
dramatic degradation, ${ }^{2}$ the idea that everyone is part of planet earth or humanity, little fear concerning the maintenance of one's own physical integrity, etc. The assessment of the degradation depends largely on its nature and how often it occurs (which is often underplayed), and also on a sense of belonging, solidarity or compassion that everyone feels towards the human and non-human victims of a disaster.

People do not consider the hazards of the environment in which they live to be responsible for the deterioration of their health so long as they believe that this environment is clean and healthy. On the other hand, they will try to blame their environment for their own physical deterioration. They highlight the phenomena they consider to be true, although this may be difficult to justify scientifically.

Nobody would hold the environment directly responsible when a native species is pushed out of its habitat by another species. Other reasons are highlighted, for example, the imbalance of the environment due to detrimental human activities.

These examples give rise to several questions. The first concerns the cultural emphasis given to the distinction between man and nature. The second concerns the idea that we have of a healthy environment and how to recover if we judge it to be degraded. The third concerns the anthropology and epistemology of science. What degree of scientific validity do we attribute to causal relationships between environment and health?

Machinery can also be subject to degradation that does not necessarily create human victims. While it is designed to withstand normal wear and tear, engineers may replace the entire unit, or its parts, in order to avoid a breakdown or other incident. Risk prevention policy terms this 'preventive maintenance' and the aim is to identify the potential degradation of a piece of equipment and anticipate any unwanted consequences. Preventive maintenance aims to maintain technical equipment in a satisfactory state.

Preventive maintenance is defined as "maintenance that is carried out at predetermined intervals or according to prescribed criteria and intended to reduce the probability of failure or degradation of the operation of a good" (extract from the French standard NF EN 13306 X 60-319). It can also take the form of scheduled maintenance, i.e. "preventive maintenance that is performed at predetermined time intervals or according to a specified number of units of use but without any preliminary check of the condition of the equipment" (extract from the French standard NF EN 13306 X 60-319), or conditional maintenance, which is defined as "preventive maintenance that is based on monitoring of the operation of the equipment and/or important parameters for its operation including the actions that result from it" (extract from the French standard NF EN 13306 X 60-319). The term 'important parameters' refers to key indicators of the equipment's condition. Finally, preventive maintenance can also take the form of predictive maintenance,

\footnotetext{
${ }^{2}$ Here we refer to a disaster rather than a catastrophe in order to respect the fact that the catastrophe is primarily the result of an intellectual construction [6]. At the time of writing, no-one knows whether the disaster will become a catastrophe.
} 
i.e. "conditional maintenance that is carried out following extrapolated forecasts and an assessment of important parameters indicating the degradation of the good" (extract from the French standard NF EN 13306 X 60-319).

Preventive maintenance relies on data that serves as objective causes of possible damage. Even at the design stage of the nuclear power plant at Fukushima Daiichi, both the idea of an earthquake occurring near the coast, and a tsunami were taken into account. To reduce the risk of the degradation of facilities, construction standards were applied. To reduce the risks created by a tsunami, dykes, able to stop waves $5.70 \mathrm{~m}$ high were erected around the plant. ${ }^{3}$ The height was based on data related to the region's history of tsunamis, seismological expertise and wave dynamics.

The construction of the Fukushima Daiichi plant that began in 1967 was based on the seismological knowledge at that time. As research continued over the years, researchers repeatedly pointed out the high possibility of tsunami levels reaching beyond the assumptions made at the time of construction, as well as the possibility of core damage in the case of such a tsunami. TEPCO ${ }^{4}$ overlooked these warnings, and the small margins of safety that existed were far from adequate for such an emergency situation [7].

In the case of the Fukushima Daiichi disaster, it is not certain that the tsunami (the cause) is the only source of the breakdowns (the effect) that led to the nuclear accident. Other causes can be highlighted, such as the earthquake, poor maintenance, or the organization of work in general.

TEPCO's report says the first wave of the tsunami reached the site at 15:27 and the second at 15:35. However, these are the times when the wave gauge set $1.5 \mathrm{~km}$ offshore detected the waves, not the times of when the tsunami hit the plant. This suggests that at least the loss of emergency power supply A at Unit 1 might not have been caused by flooding [7].

Since 2006, the regulatory authorities and TEPCO have shared information on the possibility of a total outage of electricity occurring at Fukushima Daiichi should tsunami levels reach the site. They also shared an awareness of the risk of potential reactor core damage from a breakdown of seawater pumps if the magnitude of a tsunami striking the plant turned out to be greater than the assessment made by the Japan Society of Civil Engineers. There were at least three background issues concerning the lack of improvements. First, NISA [the Japanese regulatory authority] did not disclose any information to the public on their evaluations or their instructions to reconsider the assumptions used in designing the plant's tsunami defences (...). The second issue concerned the methodology used by the Japan Society of Civil Engineers to evaluate the height of the tsunami. Even though the method was decided through an unclear process, and with the improper involvement of the electric power companies, NISA accepted it as a standard without examining its validity. A third issue was the arbitrary interpretation and selection of a probability theory. TEPCO tried to justify the belief that there was a low probability of tsunami, and used the results of a biased

\footnotetext{
${ }^{3}$ The tidal wave that followed the magnitude 9.0 earthquake occurred on 11 March, 2011 at 2:46 p. $\mathrm{m}$. local time reached its maximum height of $23.6 \mathrm{~m}$ at Ofunato, in the Iwate Prefecture, north of Fukushima Daiichi (Executive Summary of Urgent Field Survey of Earthquake and Tsunami Disasters, 25 March, 2011, Port and Import and Research Institute). The height of a tsunami varies according to many criteria. It was estimated to be about $14 \mathrm{~m}$ at Fukushima Daiichi, while the plant itself lay at $7 \mathrm{~m}$ above sea level.

${ }^{4}$ Tokyo Electric Power Company.
} 
calculation process as grounds to ignore the need for countermeasures. TEPCO also argued that basing any safety assessment against tsunami on a probabilistic approach would be using a methodology of technical uncertainties, and used that argument to postpone considering countermeasures for tsunami [7].

\section{Loss, Damage and Victims}

The term 'loss' is used to designate the consequences of degradation. In some areas, these consequences can be anticipated, while in others they cannot. For example, in an armed conflict the intentional bombing of a military building can lead to its destruction. While this may have been the intention of those who undertook the action, it can also destroy buildings or injure people who were not the target. This is referred to as 'collateral damage'. ${ }^{5}$ In this case 'damage' is most meaningful when injury has been caused to a person or group, their property, or an environment (if there is an interest in claiming compensation). Losses can be immediate or longer term.

When it concerns a person, group, non-human living species, or an environment the term 'victim' must take on a broader meaning. Not only can it be used to designate people, but also living or non-living entities that have representatives who are able to speak on their behalf. For example, the quality of a coastline is said to be degraded following an oil spill and the media do not hesitate to describe the shoreline as a 'victim'. Bees are another example. This living species is the victim of agricultural chemicals, or, as described in a French newspaper, the "victim of the lack of biodiversity". Finally, before work-related accident legislation was implemented, there were no official victims of occupational accidents or illnesses. They could not be acknowledged until dangerous working conditions or hazardous machinery was recognised. Similarly, an analysis of breakdowns due to human factors can be seen as the clumsy (or even malicious) use of machines by operators.

In general terms, there are no non-human victims. Instead, they are represented by individuals or groups who speak on their behalf and defend their interests before an authority that is responsible for estimating the loss they have suffered.

\footnotetext{
5“Collateral damage and proportionality are two inseparable concepts. The concept of proportionality in jus ad bellum reflects the balance that must be maintained between, on the one hand, military requirements and, on the other hand humanitarian interests, such as the cost in human lives. It aims to limit damage to civilians during attacks against legitimate military objectives, by weighing the military advantage that would result from the attack against the losses that it would cause to the civilian population (i.e. collateral damage). It was not until 1977 that this proportionality rule would be included in a Treaty. It is found in Articles 51, 5.b and 57, 2.b of the First Additional Protocol of 1977 to the Geneva Conventions of 1949." (emphasis added). The International Law Centre of the Free University of Brussels, https://dommagescollateraux. wordpress.com/pratique/ accessed 15 February 2015.

${ }^{6}$ Le Figaro, 25-11-2014.
} 


\section{Assessment of Compensation: An Anthropological Approach}

Once is has been established that there has been a loss, it can be estimated in economic terms. This estimate is not an end in itself. Its purpose is to provide compensation to the victim. Objective losses must be recognized by the party responsible and the victim, while its assessment is usually carried out by scientific experts and judicial authorities. Once this is done, the victim can receive compensation. Here, the purpose is to re-establish a situation that the party responsible for the damage, the victim and any third parties (scientific and/or judicial) assess as having been compromised. The new situation should be as similar as possible to the previous situation, although full recovery may be impossible. For example, the judicial process may end with the victim receiving financial and/or non-material compensation, such as a symbolic award, which takes into account any 'damages and interest' and corresponds to the non-material harm suffered by the victim. Here, the intention is to compensate for the victim's suffering.

The issue of loss should be seen in an anthropological context, that of the links that create and sustain a society. Two paradigms can be used to characterize these links.

\subsection{The Market Paradigm}

The first is the market. From a political liberalism perspective, the market represents a utility. It regulates trade, guarantees individual freedom and collective effectiveness. For example, debt repayments end an unequal relationship, in which the borrower is beholden to the lender. Once the debt is repaid, both parties are free to act and a new exchange can begin. Another example is the prison sentence, which settles a debt that the convict has to society.

In 1839 the lawyer Thimus [8] used the example of the duel to illustrate the dynamic of compensation. Here, we look at it from the perspective of natural law. In a duel, the injured party seeks redress and other party risks damage to their reputation if they refuse the challenge. Doing so would not only break the symbolic link between them, it would also negate their shared values. When community membership depends on shared values, the refusal to honour a claim for compensation ends the relationship. From the point of view of the injured party, should the other party refuse to offer compensation, they are excluded from the community.

We can transpose this relational dynamic to the Fukushima disaster. In this case, who may seek redress, and from whom? Answers to these questions require explanations that relate to the society that has suffered the injury. There are various scales. 
Any accident expresses a conflict that manifests as an imbalance between human and/or non-human entities. In the case of Fukushima Daiichi, it concerns two 'energy' entities: the plant and its environment. These are social and cultural constructions and embody antagonistic forces.

The nuclear power plant can be described in very simple or very complex terms. It can be seen as: a simple technical device that generates electricity; as a socio-technical system that regulates functional relationships between humans and machines, and between it and its environment; or in terms of a combination of human and non-human elements linked by a struggle for physical or political power. At the same time, it is the result of human activity, which is called into question from the moment it is unable to recover from the nuclear accident. Its energy takes multiple forms. ${ }^{7}$

The plant's environment is overwhelmed and transformed by natural forces: a magnitude 9.0 earthquake, followed by a tsunami.

Each of the three protagonists - the earthquake, the tsunami, and the nuclear power plant - has destructive potential, leading to an examination of the relationship between nature and the nuclear plant. In this context, the disaster represents an increase in entropy. Can it be seen as the last stage in a conflict? Using Marc Bloch's war metaphor, does the disaster that follows the accident and the disaster put an end to the conflict? "A last resort for the resolution of political disputes, war must be used to end a conflict and allow a return to equilibrium, even if fragile. However, modernity sterilises this organized violence, the capacity for destruction, the sacrifices are so great that they make it impossible to go back". 8

\subsection{The Gift Paradigm}

The second paradigm is that of the gift [9]. Unlike the market, reciprocal gift-giving corresponds to an exchange that has no beginning or end. Although the giving of a gift should not correspond to a state of indebtedness, it is nevertheless the position the receiver finds themselves in. In turn, reciprocating the gift makes the new receiver indebted. The event that led to the catastrophe can be considered as part of this relational system.

Three consequences arise. First, the system creates a long-term context, assuming that gifts continue to be exchanged. Should the receiver not reciprocate, the donor has a hold over them. Second, the gift that is given in return is never the formal equivalent of the initial gift, and the new giver must demonstrate the superiority of their gift to the initial giver. Third, the power that is expressed by the gift giver and the recipient who reciprocates makes a lasting impact on their

\footnotetext{
${ }^{7}$ This observation is not based on technical arguments; it simply refers to the ability of the nuclear reactor to destroy its own cooling mechanisms.

${ }^{8}$ Quoted by Emilio Gentile in L'apocalypse de la modernité, la grande guerre et l'homme nouveau [The Apocalypse of Modernity, the Great War and the New Man], Flammarion, 2011, p. 171.
} 
shared world view. The exchange system that unites giver and recipient requires everyone to benefit. The relational system of gift and counter-gift is ternary. Each of the elements of the exchange results in three obligations: giving, receiving and reciprocating. The exchange is based on the capacity of each party to receive, therefore to assess what is received and what should be given at a later date. Their shared understanding of what has been received defines the gift and the counter-gift and maintains the momentum.

The market and gift paradigms highlight different views of exchanges. In the case of the market, the relationship is unsustainable as it is ended by a payment. The relationship and conflict must be renewed, beginning again from zero. In the case of gift giving there is no end-point, although an inability to reciprocate unbalances the exchange and changes its modalities. The unbalanced relationship becomes fixed, and the party that cannot reciprocate becomes beholden to the gift giver. They are left at the mercy of the donor and the subject of their political decisions.

The reconciliation of these paradigms with the concept of loss appears to be a very useful heuristic. The question is: does loss correspond better to the market paradigm or the gift giving dynamic? This leads to another question: what, in both cases, drives the dynamic?

\subsection{Consequences for the Definition of the Concept of Loss}

Before considering some answers to these questions, it is first necessary to consider two important elements related to the concept of loss.

First, does the definition of loss form part of a temporally closed exchange system (e.g. a breakdown, accident and recovery) or, an open exchange system (e.g. between a disaster, an ongoing catastrophe and resilience) ${ }^{9}$ In both cases, we need to clearly define environmental, political or industrial compensation on the one hand, and the scope of resilience, on the other.

Second, we must not forget that loss can only be defined or assessed if victims can be identified. This usually requires a third party, a mediator who can identify both the loss and its victims. It assumes that the victims and the party responsible for the loss share an understanding of the situation that led to the loss and that there is no need for mediation. Identifying losses and victims becomes difficult or impossible when the victims are silent, either because they are incapable of speech or because they are not asked to speak. However, acknowledging the views of the parties involved is essential in understanding not only the material consequences of the disaster, but also its symbolic construction, considered to be one of the key phases of psychological and social resilience.

\footnotetext{
${ }^{9}$ Here, ecological resilience refers to the ability of the overall system to rebalance itself in the long term; it does not necessarily mean that it returns to the state that it was in prior to the disaster, which may be impossible to achieve [10].
} 


\section{The Fukushima Daiichi Catastrophe as a Total Social Fact}

The relationship between people, whether they be settlements in the neighbourhood of the Fukushima Daiichi plant or humanity in its entirety (defined either as anything that belongs to the human species on the one hand, or other material and natural elements on the other hand) must be taken into account if the definition of the nuclear catastrophe is to go beyond technical aspects. As time passes, the catastrophe must be seen as a 'total social fact' and the dynamic is that of reciprocal gift giving. On the one hand, the elements that make up this relational system can be considered as an endless sequence of actions and reactions (sometimes referred to as a chain reaction), which describe an inevitable succession of events (rather than a causal chain). On the other hand, it must make it possible to clearly identify the victims of the accident, then the disaster, how victims emerge, the balance between them and the losses they have suffered, and therefore to determine the extent of their losses in the context of an exchange defined by the social (and potentially natural) limits of 'resilience'. Ecological resilience corresponds to changes in an environment that is affected by a catastrophe, which leads to a more stable situation where the consequences of the catastrophe are physically or symbolically mitigated.

\section{A Choice of Paradigm?}

The market or the exchange of gifts? The market is governed by rules applied by statutory law, while the dynamics of gift giving are rooted in the philosophical presuppositions of natural law. Statutory law reflects the actual legal position of a society at a given time. It is made up of regulations governing, for example, trade. On the other hand, natural law allows and protects the expression of human nature; it addresses universal principles. For example, [11] considered that it was based on two principles that preceded reason. Nowadays, this would be what is not covered by instrumental or logical rationality: self-love and altruistic pity are two practices that form the foundations for human relationships. These two principles suggest a universal human nature that falls short of the rational rules that govern collective action. However, despite the universality that philosophers and law-makers of the Enlightenment sought to give it (notably through the Declaration of the Rights of Man and the Citizen) natural law has been discussed in terms of its potential relativity in space-time. The inclusion of local and traditional cultures changes the idea that men are the product of their relationships with each other or their environment. Ways of living together become defined for both humans and non-humans, which show that the idea of human nature is historically and culturally relative. This is manifested, for example, through the definition that each individual has of human health or an acceptable level of pollution. The ensuing discussion 
focuses on a universal definition of health (e.g. the World Health Organisation) and negotiations to establish indicators, then standards for environmental pollution. Other debates focus on securing financial compensation for victims, the social acceptability of a hazardous technology, or the pristine condition of a shoreline prior to environmental clean-up or decontamination, etc.

The search for the foundations of natural law corresponds to the desire to define, then respect 'the' or ' $a$ ' human nature. The latter cannot be distinguished from nature itself, which is here defined as what surrounds human beings. Both the history of ideas about human nature and growing awareness of environmental degradation show the need to reduce the philosophical, political, moral and economic divide between Man and Nature. This is not without consequences. It means that:

(a) In the context of Fukushima Daiichi, Nature (made up of human and non-human elements) should be considered as an integral victim of the accident and the ongoing catastrophe, and should be able to claim compensation. This would force people to redefine their moral responsibility vis-à-vis the impact of their activities on the environment.

(b) Distinguishing the three elements that made up the events of 11 March, 2011 suggests that only the nuclear accident was the source of the damage to the environment. The accident cannot be likened to a simple natural disaster, just because there was an earthquake and a tsunami. Nature cannot be considered as a victim of itself, nor can a natural event be distinguished from a manifestation of Nature. The argument simply lends weight to an anthropocentric perspective that maintains the divide between Nature and human nature. Nature is constantly evolving, and the distinction between how this happens (e.g. low-level changes or sudden and dramatic events) may reinforce the anthropocentric tendency.

The distinction between a natural event and a nuclear accident makes it possible to think about two types of resilience: the first relates to the self-regulation of Nature, which is constantly changing and can never be considered as the return to a previous state; while the second relates to human resilience and focuses on life during and after the disaster.

An illustration of this comes from Fukushima Daiichi (or Chernobyl) where a decision was taken to establish no-go zones around the facility. This type of decision implicitly reaffirmed the divide between human and non-human beings. It designates humans as the most important victims of the ongoing disaster. However, the decision to ban fishing or hunting in areas adjacent to the no-go zone shows than there were other victims.

(c) Although the earthquake and tsunami led to the destruction of nature, humans did not see it as a victim. However, this depends on the anthropological status that is assigned to it. Moving a random stone may not lead to a claim for damages, while moving another that is part of a dyke or historic monument can lead to funds being allocated for its reconstruction. In the first case, the stone does not have victim status, it the second, it does. The same argument can be 
made about living species. Whether they are designated as victims will depend on the degree of domestication or their value in terms of heritage (e.g. protected and other endangered species). In all cases, the designation as a victim of a natural event depends on the degree of humanization attributed to living or inanimate natural elements. This attribution can be implied or voluntary, traditional or political.

It must be noted that the Fukushima Daiichi accident could only have been caused by humans, even if other elements contributed to material, imaginary and symbolic construction of the catastrophe. ${ }^{10}$ First and foremost, the plant was created by humans. In simple terms, if the plant had not existed, there would have been no nuclear accident $!^{11}$

The nuclear accident is therefore unlike the earthquake or tsunami. The identification of those responsible and victims is indicative of instrumental thinking and statutory law. The accident finds its origin in the fact that humans have used nuclear fission to generate electricity, and they designed the necessary technology; while external natural forces (the earthquake followed by the tsunami) damaged the plant, they did not create an imminent danger to the environment. Radioactivity is a natural (re)action that has been exploited by humans and become an organised, industrial activity ${ }^{12}$ designed to produce electricity. The nuclear accident and its consequences were an assault on the technology's environment and made it dangerous or unliveable for its inhabitants.

Not only humans, but also their pets were evacuated from around the Fukushima-Daiichi plant. $^{13}$

The investigations that are being carried out into the accident and the ensuing devastation seek to determine the responsibilities of human beings. They focus on why the plant was built, why it was located in an area subject to earthquakes and tsunamis, construction techniques, the use of data to assess the risk of earthquakes and tsunamis, ${ }^{14}$ etc. Their findings will determine who is responsible and the human and non-human victims. In time, their understanding of the disaster will become part of local and international statutory law. Investigations that seek to establish who is responsible will address questions such as: were emergency services sufficiently responsive and appropriate to the situation? Were anti-seismic building codes met? Did land-use plans take account of the risk of a tsunami? Was a full risk

\footnotetext{
${ }^{10}$ See [12]. The construction of the catastrophe can be viewed in terms of its material, imaginary dimensions (fantasies, individual and collective representations) and symbolic (collective meaning attributed to material phenomena and individual and collective representations) dimensions.

${ }^{11}$ This observation forms the basis for radical anti-nuclear protests. See [13].

${ }^{12}$ Sometimes called the domestication of nature.

${ }^{13} \mathrm{http} / / / \mathrm{www}$.actu-environnement.com/ae/news/japon-evacuation-animaux-centrales-fukushimaifaw-12578.php4.

${ }^{14}$ See the article "Tsunami: les ancêtres savaient [Tsumani: the ancestors knew]", published in the French newspaper Le Monde on 6 May 2011. Available online at http://www.lemonde.fr/japon/ article/2011/05/06/tsunami-les-ancetres-savaient_1517972_1492975.html.
} 
assessment carried out? Was the plant in a satisfactory condition? What controls and maintenance procedures were in place? Were they sufficiently rigorous and respected? Was the data related to the plant's design and technical operations satisfactory? In the event that these investigations and the courts identify particular weaknesses or shortcomings, the victims will receive financial and/or symbolic compensation. These 'gifts' will contribute to resilience that will act as a reciprocal gift, thereby creating new human requirements, such as gifts to the environment.

\section{Conclusion}

Our work looks the question of the losses resulting from the nuclear accident at Fukushima Daiichi from multiple perspectives: natural and statutory law; compensation based on the market paradigm and that of gift-giving; and the designation of victims, losses and compensation. On the latter point, it seems interesting to think in terms of a kind of non-radical environmentalism. ${ }^{15}$

The situation is already a reality. Tawada [16] points out that "there is no Japanese word that is an exact translation for the German work 'catastrophe'. In German, the word is used in relation to nature and politics. In the event of a natural catastrophe, politics comes readily to the mind of people." While [12] considers that "it has become impossible to clearly separate the movements of political change from those that lead to an environmental threat. It is seen in the symbolic dimension of the catastrophe, the overturning of the world of meanings leading to the revelation of a gap where legislation was supposed to take over." From this flows the importance of understanding how compensation can be used to fill the gap.

The catastrophe began on 11 March, 2011 and it does not yet appear to have reached its end. Many observers believe that it is just beginning. Current discussions focus on two areas: an objective explanation of the disaster that initiated the catastrophe; and the designation of victims and the assessment of losses. But who will be invited to the discussions and for how long? It must not be forgotten that in French the word 'loss' is equivalent to the concept of "harm or damage caused to someone or something" (Dictionnaire Littré). This presupposes a dramatic event that takes place over some time (with the idea that the timeframe widens-or notits scope). It also presupposes that it is possible to identify the persons or things that

\footnotetext{
${ }^{15}$ Afeissa [14] [15] defines environmental ethics as an ethic "which produces a new object, the non-human natural world, judged worthy of moral consideration on its own merits, in other words regardless of any coefficient of utility for the existence of man and considered as a place of intrinsic value or as a holder of rights whose existence as such, command a number of moral and legal obligations." It raises several questions that this article seeks to clarify: To whom should natural rights (of Man or Nature) be given? Can it be done, and can we assign rights to non-humans without strengthening an anthropocentric perspective leading to radical monism? Who can claim these rights (humans, non-humans) and, in the case of non-humans, how does this manifest? Who attributes such rights? In particular, who speaks on behalf of whom?
} 
have or will suffer harmful effects, either immediately or at a later stage. The definition of losses requires the identification of all persons and things marked by the event and an attempt to establish causal relationships between them. Epistemological caution should inform these discussions, their development and the decisions that remain to be taken.

This chapter is part of broader thinking on resilience engineering applied to the Fukushima Daiichi catastrophe. But is it the time to talk about resilience, when we still do not really know if the catastrophe is over. What is resilience? In the case of Fukushima Daiichi, resilience refers to the capacity of a technical system to continue operating, or to resist further damage in an unfavourable environment. It also refers to the ability of an ecosystem to recover its operations or development as they were before the system was disturbed.

Losses require the evaluation and implementation of compensatory measures that are designed to cancel out any injury to humans or non-humans who are designated as victims of the disaster. The aim of these practices is to restore harmony to the relationship between a victim (human or non-human) and the party responsible (human or non-human). In all cases, the assessment of losses and the implementation of measures designed to compensate for the harm suffered (reciprocal gift-giving) help to create shared meaning. We argue that this construction relates to resilience to catastrophe. The meaning that this evokes must form part of the preamble to such practices. A shared understanding appears to be necessary to think about resilience. A shared vision and sensitivity to, a minima, what needs to be considered, foreseen, done, and said is necessary for the construction of new meanings and practices linked to resilience. The definition of loss therefore presupposes many other shared intentions: to carry out repairs, and manage resilience in the best way possible. Practical and technical issues must be addressed, which must not overlap, merge or lead to the same answers. The redefinition of loss is perhaps an indicator of a consensus, if it can be accepted by the various stakeholders.

\section{References}

1. H.-P. Jeudy, Le désir de catastrophe (Circe-Poche, Paris, 1990)

2. R. Barbier, J.-Y. Trepos, Humains et non-humains: un bilan d'étape de la sociologie des collectifs. Revue d'anthropologie des connaissances, 1, 35-58 (2007)

3. B. Latour, Une sociologie sans objet? Note théorique sur l'interobjectivité. Sociologie $d u$ Travail 36 (4), 587-607 (1994)

4. D. Anzilotti, La responsabilité internationale des États à raison des dommages subis par les étrangers, Revue générale de droit international, 13, 13-29 (1906)

5. B. Latour, Enquête sur les modes d'existence.Une anthropologie des Modernes (La découverte, Paris, 2012)

6. Ailloud-Nicolas, Scènes de théâtre: Le tremblement de terre de Lisbonne (1755) et Le Jugement dernier des rois (1793), in L'invention de la catastrophe au XVIIIe siècle. Du châtiment divin au désastre naturel, ed. by A.M. Mercier-Faivre, C. Thomas (Droz, Geneva, 2008) 
7. The Fukushima Nuclear Accident Independent Investigation, Commission Official Report, The National Diet of Japan (2012)

8. F.-G.-J. Thimus, Manuel de Droit Naturel ou de Philosophie du Droit [1839] (Nabu Press, 2012)

9. M. Mauss, Essai sur le don. Forme et raison de l'échange dans les sociétés primitives, [19231924], in Sociologie et anthropologie (Presses universitaires de France, Paris, 1968)

10. D. Pécaud, Méthodologie de retours d'expérience: concepts, finalités et conditions, in Les conséquences du naufrage de l'Erika, Risques, environnement, société, rehabilitation, ed. by J.-P. Beurier, Y.-F. Pouchus (Presses Universitaires de Rennes, 2005)

11. J.-J. Rousseau, Discours sur l'origine et les fondements de l'négalité parmi les hommes [1753] (Gallimard, Paris, 1965)

12. S. Le Poulichet, Environnement et Catastrophe (Mentha, Paris, 1991)

13. S. Topçu, La France nucléaire, l'art de gouverner une technologie contestée (Seuil, Paris, 2013)

14. H.S. Afeissa, La communauté des êtres de nature (MF, Paris, 2007)

15. Ethique de l'environnement, Nature, valeur, respect, textes réunis par Afeissa H. S. (Vrin, Paris, 2007)

16. Y. Tawada, Journal des jours tremblants (Verdier, Paris, 2012)

Open Access This chapter is licensed under the terms of the Creative Commons Attribution 4.0 International License (http://creativecommons.org/licenses/by/4.0/), which permits use, sharing, adaptation, distribution and reproduction in any medium or format, as long as you give appropriate credit to the original author(s) and the source, provide a link to the Creative Commons license and indicate if changes were made.

The images or other third party material in this chapter are included in the chapter's Creative Commons license, unless indicated otherwise in a credit line to the material. If material is not included in the chapter's Creative Commons license and your intended use is not permitted by statutory regulation or exceeds the permitted use, you will need to obtain permission directly from the copyright holder.

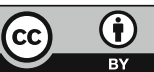

